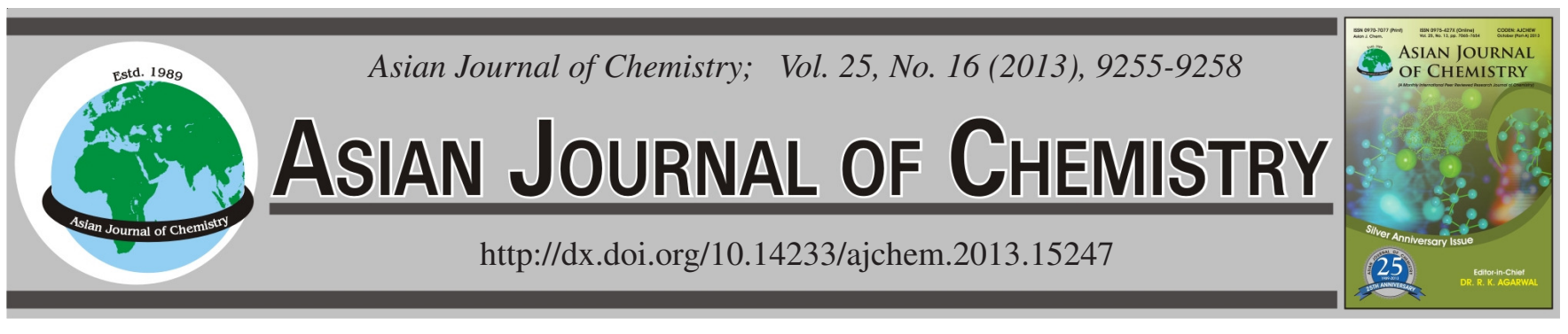

\title{
Preparation and Characterization of Nano-Barium Titanate Based on Glass Fiber Filter and its Application in Preconcentration of Heavy Metals in Environmental Water
}

\author{
YAN Li and Dong ZHANG*
}

School of Environmental and Chemical Engineering, Shenyang Ligong University, Shenyang 110159, P.R. China

*Corresponding author: Tel./Fax :+ 8624 24680345; E-mail: sylgdxdong@ sina.com

Nano-barium titanate based on glass fiber filter (GFBT) was successfully prepared by sol-gel method and characterized using XRD and SEM. The adsorptive potential of GFBT for heavy metal ions, such as lead, cadmium, zinc, nickel, copper and silver, was investigated. The results showed that the nano-barium titanate could crystal based on glass fiber, gaining a new block adsorbent like a leaf. The lead, cadmium, zinc, nickel, copper and silver ions were quantitatively retained at $\mathrm{pH} 5-9$; their adsorption capacities of GFBT for lead, cadmium, zinc, nickel, copper and silver ions were 155.93, 22.38, 35.98, 3.97, 81.92 and $15.32 \mathrm{mg} / \mathrm{g}$, respectively. The adsorbent can be regenerated completely by elution with $1 \mathrm{~mol} / \mathrm{L} \mathrm{HNO}_{3}$. The method has been applied to the simultaneous preconcentration of trace amounts of lead, cadmium, zinc, nickel, copper and silver in environmental water with satisfactory results.

Key Words: Nano-barium titanate, Glass fiber filter, Adsorption, Heavy metals, Water.

\section{INTRODUCTION}

Over the past few decades, the pollution of the environment by heavy metals has received considerable attention. It distributed widely in the environment and produces several diseases. It has been ranked as environmental priority pollutant in many countries. Therefore, it is important to monitor the levels of heavy metals in environments. Several analytical techniques such as atomic absorption spectrometry (AAS) and inductively coupled plasma spectrometry (ICP) are available for the determination of heavy metals with sufficient sensitivity for most of the applications ${ }^{1}$. However, it is hard to directly determine extremely low concentrations of the required trace elements by these methods without pre-separation and enrichment. The limitations are associated not only with the insufficient sensitivity of these techniques but also with matrix interference. For this reason, preliminary separation and preconcentration of trace elements from matrix is often required. The most widely used techniques for the separation and preconcentration of trace elements include liquid-liquid extraction ${ }^{2}$, co-precipitation $^{3}$, ion-exchange ${ }^{4}$, cloud point extraction ${ }^{5}$, solidphase extraction ${ }^{6-9}$. Recently, as a new solid-phase extractant, nano-titanate, included nanometer barium-strontium titanate, nano-calcium titanate, has been successfully applied in separation and enrichment ${ }^{10,11}$. However, since nano-titanate powder is so small that, when used in adsorption of metal ions, it was easy to coacervate and lose activity and is difficult to recover. Fixing nano-titanate onto different substrates corrects these problems with satisfactory results ${ }^{12-15}$. But nano-barium titanate based on glass fiber filter used in preconcentration of trace heavy metal has not been studied. In this work, nanobarium titanate based on glass fiber filter (GFBT) was successfully prepared by sol-gel method and a new block adsorbent was obtained, the adsorptive potential of GFBT for the preconcentration of trace lead, cadmium, zinc, nickel, copper and silver ions were assessed using the batch adsorption method. A new method using GFBT as solid-phase extraction agent has been developed for the preconcentration of trace lead, cadmium, zinc, nickel, copper and silver in water sample analyses by FAAS.

\section{EXPERIMENTAL}

$\mathrm{X}$-Ray diffraction (XRD) on the nano-barium titanate based on glass fiber filter (GFBT) was performed using a D/max-RB X-ray diffractometer (Rigaku Corporation Japan). Images of the glass fiber filter and the GFBT were taken using an S-3400N scanning electronic microscope (Hitachi Japan). The parameters for all machines were adjusted according to the manufacturer's recommendations.

WYX-9003A atomic absorption spectrometer (Shenyang Yi Tong Analytical Instrument Co., Ltd.), equipped with hollow cathode lamps for lead, cadmium, zinc, nickel, copper and silver as the radiation source were used for analysis. The operating conditions were summarized in Table- 1 . 


\begin{tabular}{cccccc}
\hline \multicolumn{6}{c}{ TABLE-1 } \\
Element & $\begin{array}{c}\text { Wave } \\
\text { length } \\
(\mathrm{nm})\end{array}$ & $\begin{array}{c}\text { Spectral } \\
\text { band width } \\
(\mathrm{nm})\end{array}$ & $\begin{array}{c}\text { Lamp } \\
\text { current } \\
(\mathrm{mA})\end{array}$ & $\begin{array}{c}\text { Burner } \\
\text { height } \\
(\mathrm{mm})\end{array}$ & $\begin{array}{c}\text { Acetylene gas } \\
\text { consumption } \\
\left(\mathrm{L} \mathrm{min}^{-1}\right)\end{array}$ \\
\hline $\mathrm{Pb}$ & 283.4 & 0.4 & 2.0 & 5.0 & 1.5 \\
$\mathrm{Cd}$ & 228.8 & 0.4 & 2.0 & 5.0 & 1.0 \\
$\mathrm{Zn}$ & 213.9 & 0.4 & 6.0 & 7.0 & 2.0 \\
$\mathrm{Ni}$ & 232.0 & 0.2 & 8.0 & 5.0 & 1.3 \\
$\mathrm{Cu}$ & 324.8 & 0.4 & 3.6 & 6.0 & 1.8 \\
$\mathrm{Ag}$ & 328.1 & 0.4 & 4.0 & 7.0 & 2.2 \\
\hline
\end{tabular}

The $\mathrm{pH}$ values were measured with a PHS-3C acidometer (Shanghai REX Instrument Factory, Shanghai, China) supplied with a combined electrode.

A constant temperature bath shaker (Jintan Experiment Instrument Factory, Jiangsu China) was used for adsorption and desorption experiments.

Glass fiber filter was special for determination of TSP/IP by gravimetric method in environmental monitoring (Shi Jia Zhuang Lage Sci \& Development Co., Ltd). The reagents, $\mathrm{Ba}\left(\mathrm{NO}_{3}\right)_{2}$ and citric acid, were analytical grade. Tetrabutyl titanate was chemically pure. Stock solutions of lead, cadmium, zinc, nickel, copper and silver were prepared by dissolving each metal (purity $>99.99 \%$ ) in a small amount of $1+1$ nitric acid separately and diluting to $1000 \mathrm{~mL}$ with $0.1 \%$ nitric acid. Working standard solutions were prepared by appropriate dilution of the stock standard solutions. The water in this study was distilled water.

Preparation of the GFBT: Barium titanate sol was synthesized by the citrate precursor method. For the preparation of the precursor solution, barium nitrate, tetrabutyl titanate, citric acid and ethylene glycol (EG-1500) were used as starting materials. First, a specific amount of tetrabutyl titanate was dissolved into ethanol. The mixture was stirred until it became transparent and yellow. Subsequently, citric acid were direct added to this solution on a magnetic stirrer and the solution came back to clear. Then, barium nitrate and ethylene glycol solutions were added to this solution. The mixture was stirred continuously until it became a clear solution, pale brown in colour. Then, ammonium hydroxide solution was added to the precursor solution to adjust the $\mathrm{pH}$ value of 3.0.

The glass fiber filter calcined at $500{ }^{\circ} \mathrm{C}$ for $1 \mathrm{~h}$ and was cooled to room temperature in a desiccator. It was immersed in the prepared barium titanate sol for $0.5 \mathrm{~h}$ and then taken up and put in drying oven for drying at $105^{\circ} \mathrm{C}$. This process was repeated three times. The dried glass fiber filter was burned at $500{ }^{\circ} \mathrm{C}$ for $6 \mathrm{~h}$ under air atmosphere. Subsequently, it was cooled to room temperature in a desiccator. Nano- barium titanate based on glass fiber filter (GFBT) was immersed in $1 \mathrm{~mol} / \mathrm{L} \mathrm{HNO}_{3}$ for $0.5 \mathrm{~h}$. After washing to neutral with water, it was dried at $105^{\circ} \mathrm{C}$ and stored in a desiccator.

General procedure: A specific amount of metal ion solution was placed into a $50 \mathrm{~mL}$ calibrated beaker flask with plug. The $\mathrm{pH}$ was adjusted to 6 with nitric acid or ammonia solution. After dilution to the mark with water, $0.1 \mathrm{~g}$ of GFBT was added. Covered with a plug, the beaker flask was shaken for $15 \mathrm{~min}$ in a constant temperature bath shaker (200 r/min). Then the supernatant fluid was directly inhaled into the atomic absorption spectrometer, where the concentrations of lead, cadmium, zinc, nickel, copper and silver ions were determined by FAAS and absorption capacity was calculated. Then the GFBT was washed with water and the adsorbed metal ions were eluted with $5 \mathrm{~mL}$ of $1 \mathrm{~mol} / \mathrm{L} \mathrm{HNO}_{3}$ solution by shaking for $5 \mathrm{~min}$. The concentrations of the metal ions in the eluents were determined by FAAS. Recoveries were calculated from concentrations of supernatants and eluents.

\section{RESULTS AND DISCUSSION}

Characterization of GFBT: The X-ray diffraction patterns for glass fiber filter and GFBT are shown in Fig. 1. It can be seen that the glass fiber filter was noncrystal (line 1), the sharps at 22.18, 31.58, 38.94, 45.22, 56.22 and 65.90 can be attributed to barium titanate (line 2). It can be concluded that barium titanate loaded on the glass fiber filter had a perovskite structure. According the Scherrer equation, the average particle diameter of strontium titanate loaded on the glass fiber filter can be calculated ${ }^{4}$.

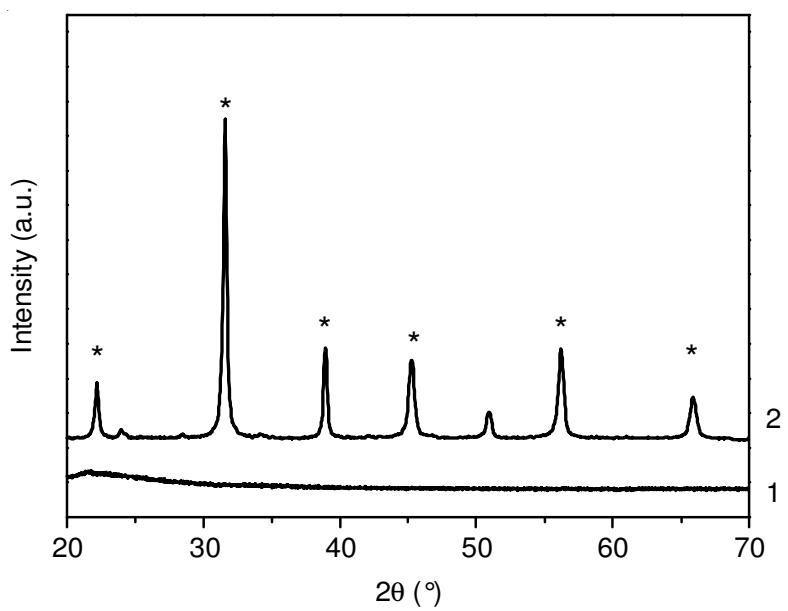

Fig. 1. XRD patterns of glass fiber filter and GFST (1) Glass fiber filter; (2) GFBT

The SEM images of the glass fiber filter and GFBT are shown in Fig. 2A-C, respectively. The SEM images show that barium titanate is shown on the surface of glass fiber. The barium titanate could crystal based on glass fiber, gaining a new block adsorbent like a leaf.

Effect of pH on adsorption: In order to evaluate the effect of $\mathrm{pH}$, the $\mathrm{pH}$ values of sample solutions were adjusted to a range of 1-10 with $\mathrm{HNO}_{3}$ or $\mathrm{NH}_{3} \cdot \mathrm{H}_{2} \mathrm{O}$, respectively. The results of the effect of $\mathrm{pH}$ on the adsorption percentage of studied ions are shown in Fig. 3A-B, respectively. It could be seen that the adsorption rates of $\mathrm{Pb}^{2+}, \mathrm{Cd}^{2+}, \mathrm{Zn}^{2+}, \mathrm{Ni}^{2+}, \mathrm{Cu}^{2+}$ and $\mathrm{Ag}^{+}$ on the glass fiber filter were all near zero, while the adsorption capacity of GFBT to $\mathrm{Pb}^{2+}, \mathrm{Cd}^{2+}, \mathrm{Zn}^{2+}, \mathrm{Ni}^{2+}, \mathrm{Cu}^{2+}$ and $\mathrm{Ag}^{+}$was high and $\mathrm{pH}$ dependent. The adsorption of $\mathrm{Pb}^{2+}$ at the $\mathrm{pH}$ range of 3-10, of $\mathrm{Cd}^{2+}$ and $\mathrm{Ag}^{+}$at the $\mathrm{pH}$ range of 5-10, of $\mathrm{Ni}^{2+}$ at the $\mathrm{pH}$ range of 5-9, of $\mathrm{Zn}^{2+}$ at the $\mathrm{pH}$ range of 4-10 and of $\mathrm{Cu}^{2+}$ at the $\mathrm{pH}$ range of 6-10 was over $98 \%$. In order to adsorb $\mathrm{Pb}^{2+}$, $\mathrm{Cd}^{2+}, \mathrm{Zn}^{2+}, \mathrm{Ni}^{2+}, \mathrm{Cu}^{2+}$ and $\mathrm{Ag}^{+}$simultaneously and to avoid the precipitation of metal ions at high concentration, $\mathrm{pH} 6$ was selected in this work.

Effect of shaking time: At room temperature, the adsorption capacities for lead, cadmium, zinc, nickel, copper and 


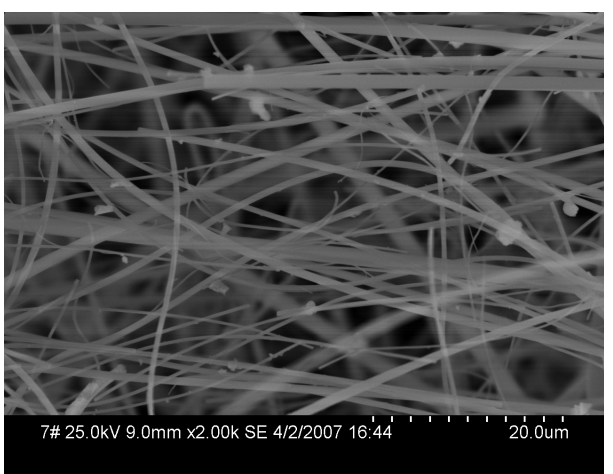

(A)

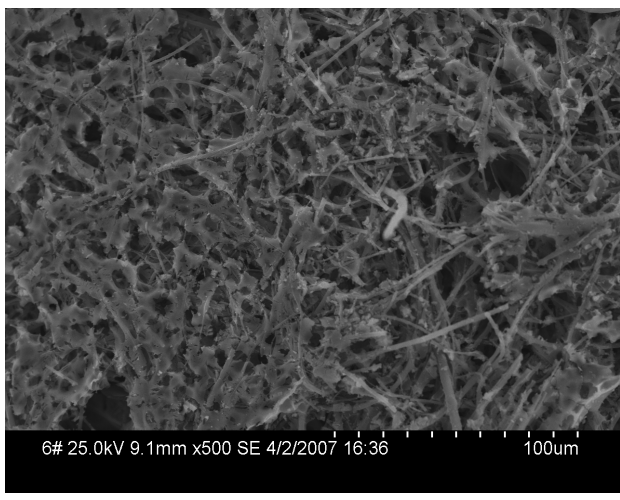

(B)

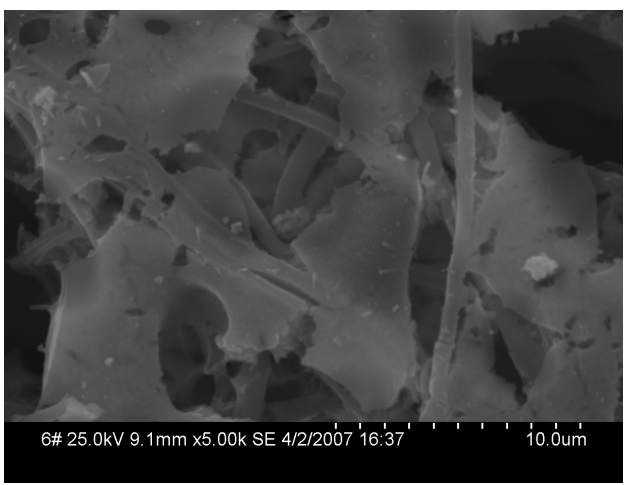

(C)

Fig. 2. (A) SEM images of glass fiber filter. (B) SEM images of GFBT (X500). (C) SEM images of GFBT (X5000)

silver ions were determined with different shaking times (Fig. 4). The results indicate that the adsorption capacity increased with an increase in shaking time and reached equilibrium at 5 min for $\mathrm{Pb}, \mathrm{Zn}, 10 \mathrm{~min}$ for $\mathrm{Ni}$ and $15 \mathrm{~min}$ for $\mathrm{Cd}, \mathrm{Cu}, \mathrm{Ag}$. Therefore, the shaking time was $15 \mathrm{~min}$ in this study.

Static adsorption capacity: According to Fig. 4, at room temperature, the static adsorption capacities of GFBT to lead, cadmium, zinc, nickel, copper and silver were $155.93 \mathrm{mg} / \mathrm{g}$, $22.38,35.98,3.97,81.92$ and $15.32 \mathrm{mg} / \mathrm{g}$, respectively.

Elution of the adsorbed metal ions: It was found from Fig. 3B that the adsorption of cations at $\mathrm{pH} \leq 1$ could be negligible. So, after the heavy metal ions were adsorbed under the optimized adsorption conditions, $5 \mathrm{~mL}$ of $\mathrm{HNO}_{3}(0.05 \mathrm{~mol} / \mathrm{L}-$ $2.5 \mathrm{~mol} / \mathrm{L}$ ) were used for elution for $5 \mathrm{~min}$. The results showed that the recovery increased with an increase of $\mathrm{HNO}_{3}$ concentration. When the concentration of $\mathrm{HNO}_{3}$ was higher than 0.5 $\mathrm{mol} / \mathrm{L}$, the recoveries were all up to $98 \%$. Therefore, for

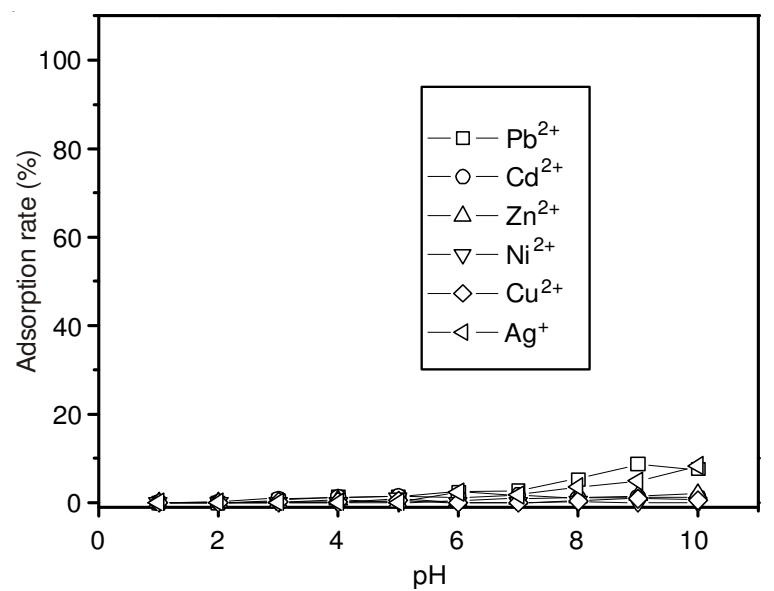

(A)

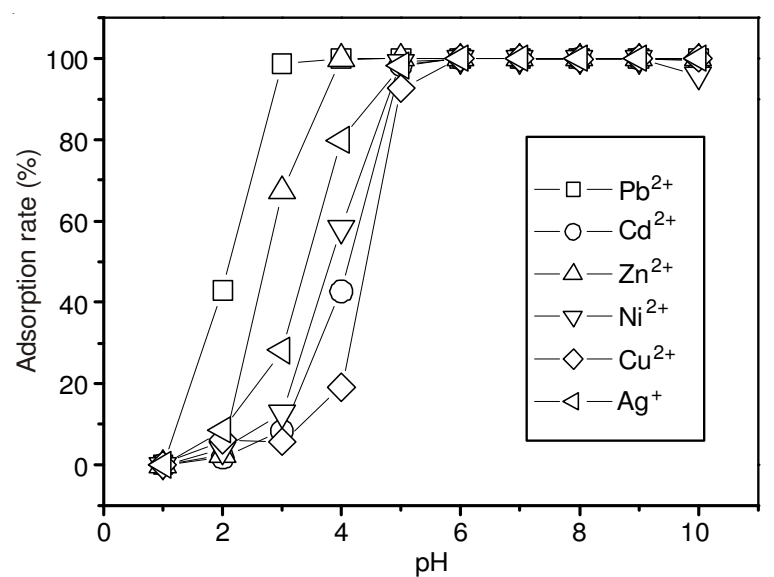

(B)

Fig. 3. (A) Effect of $\mathrm{pH}$ on the adsorption of the metal ions on glass fiber filter. (B) Effect of $\mathrm{pH}$ on the adsorption of the metal ions on GFBT

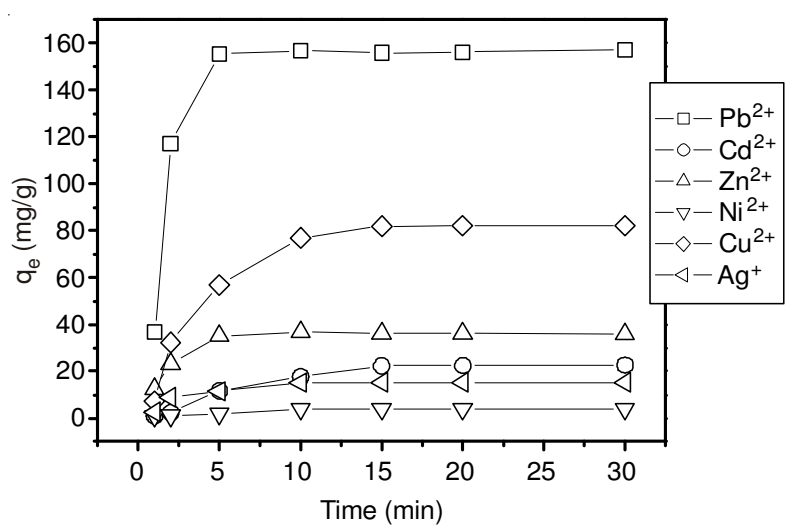

Fig. 4. Effect of shaking time on the adsorption of the studied metal ions on GFBT

sufficient elution, $1 \mathrm{~mol} / \mathrm{L} \mathrm{HNO}_{3}$ was chosen. After elution, the GFBT was washed with water, dried and reused 10 times. Its adsorption performance did not decrease, indicating that this adsorption agent was very stable.

Enrichment factor and detection limit: In order to explore the possibility of enriching low concentrations of analytes from large volumes, the effect of sample volume on the retention of heavy metal ions was also investigated. For this purpose, 25, 50, 100, 250 and $500 \mathrm{~mL}$ of sample solution containing $20 \mu \mathrm{g}$ of $\mathrm{Pb}^{2+}, 5 \mu \mathrm{g}$ of $\mathrm{Cd}^{2+}, \mathrm{Zn}^{2+}, \mathrm{Ni}^{2+}, \mathrm{Cu}^{2+}$ and $\mathrm{Ag}^{+}$respectively. After adsorption, the samples were eluted 
with $5 \mathrm{~mL}$ of elution liquid. The results show that the recoveries was reduce with the increase of solution volume. When the solution volume was $500 \mathrm{~mL}$ the recoveries were all above $95 \%$. The enrichment factor was 100 . The detection limits were calculated using the concentration of three times standard deviation, calculated from 11 runs of the blank solution with concentrations of $\mathrm{Pb}^{2+}, \mathrm{Cd}^{2+}, \mathrm{Zn}^{2+}, \mathrm{Ni}^{2+}, \mathrm{Cu}^{2+}$ and $\mathrm{Ag}^{+}$at 0.17 , $0.024,0.016,0.058,0.012$ and $0.018 \mu \mathrm{g} / \mathrm{L}$, respectively.

Effects of coexisting ions: The effects of common coexisting ions on the adsorption were investigated. In these experiments, potential interfering ions were added to solutions of $0.2 \mathrm{mg} / \mathrm{L} \mathrm{Pb}^{2+}, 0.02 \mathrm{mg} / \mathrm{L} \mathrm{Cd}^{2+}, \mathrm{Zn}^{2+}, \mathrm{Ni}^{2+}, \mathrm{Cu}^{2+}$ and $\mathrm{Ag}^{+}$. The experimental results showed that the recoveries of the target analytes remained above $95 \%$ even in the presence of ions in the following concentrations: $1000 \mathrm{mg} / \mathrm{L}$ for $\mathrm{Na}^{+}, \mathrm{K}^{+}, \mathrm{NH}_{4}{ }^{+}$and $\mathrm{NO}_{3}{ }^{-} ; 500 \mathrm{mg} / \mathrm{L}$ for $\mathrm{Al}^{3+}, \mathrm{Ca}^{2+}$ and $\mathrm{Mg}^{2+} ; 100 \mathrm{mg} / \mathrm{L}$ for $\mathrm{PO}_{4}^{3-}$ and $\mathrm{Cr}(\mathrm{VI}) ; 50 \mathrm{mg} / \mathrm{L}$ for $\mathrm{Cr}(\mathrm{III}), \mathrm{Co}^{2+}$; and $20 \mathrm{mg} / \mathrm{L}$ for $\mathrm{Fe}^{3+}$, indicating that the method has a good tolerance to matrix interference.

Analysis application: River water samples collected from Liao He and Hun He rivers (Shenyang, China), were filtered through a $0.45 \mu \mathrm{m}$ membrane filter. According to the general procedure, metal ions were adsorbed on the GFBT. Then were eluted and determinate the $\mathrm{Pb}^{2+}, \mathrm{Cd}^{2+}, \mathrm{Zn}^{2+}, \mathrm{Ni}^{2+}, \mathrm{Cu}^{2+}$ and $\mathrm{Ag}^{+}$ with FAAS, respectively. Meanwhile, the recovery tests were also conducted. The results were given in Tables 2 and 3, respectively. The results indicated that the recoveries were reasonable for trace analysis, in a range of 93-107.6\%.

\begin{tabular}{|c|c|c|c|}
\hline \multicolumn{4}{|c|}{$\begin{array}{c}\text { TABLE-2 } \\
\text { DETERMINATION OF HEAVY METAL } \\
\text { IONS IN HUN HE RIVER WATER SAMPLE }\end{array}$} \\
\hline Element & Added (mg/L) & Founded $(\mathrm{mg} / \mathrm{L})$ & Recovery (\%) \\
\hline \multirow{3}{*}{$\mathrm{Pb}^{2+}$} & 0 & 0.0481 & - \\
\hline & 0.02 & 0.0687 & 103 \\
\hline & 0.05 & 0.1019 & 107.6 \\
\hline \multirow{3}{*}{$\mathrm{Cd}^{2+}$} & 0 & 0.0039 & - \\
\hline & 0.002 & 0.0058 & 95 \\
\hline & 0.005 & 0.0091 & 104 \\
\hline \multirow{3}{*}{$\mathrm{Zn}^{2+}$} & 0 & 1.0337 & - \\
\hline & 0.5 & 1.5085 & 94.96 \\
\hline & 1 & 1.9986 & 96.49 \\
\hline \multirow{3}{*}{$\mathrm{Ni}^{2+}$} & 0 & 0.0151 & - \\
\hline & 0.01 & 0.0248 & 97 \\
\hline & 0.05 & 0.0661 & 102 \\
\hline \multirow{3}{*}{$\mathrm{Cu}^{2+}$} & 0 & 0.8782 & - \\
\hline & 0.5 & 1.3804 & 100.44 \\
\hline & 1 & 1.861 & 98.28 \\
\hline \multirow{3}{*}{$\mathrm{Ag}^{2+}$} & 0 & n.d. & - \\
\hline & 0.01 & 0.0093 & 93 \\
\hline & 0.02 & 0.0189 & 94.5 \\
\hline
\end{tabular}

\section{Conclusion}

Nano-barium titanate based on glass fiber filter (GFBT) was successfully prepared and a new block adsorbent like a leaf was used for heavy metal ions adsorption. The lead, cadmium, zinc, nickel, copper and silver were quantitatively

\begin{tabular}{|c|c|c|c|}
\hline \multicolumn{4}{|c|}{$\begin{array}{c}\text { TABLE-3 } \\
\text { DETERMINATION OF HEAVY METAL } \\
\text { IONS IN LIAO HE RIVER WATER SAMPLE }\end{array}$} \\
\hline Element & Added (mg/L) & Founded $(\mathrm{mg} / \mathrm{L})$ & Recovery $(\%)$ \\
\hline \multirow{3}{*}{$\mathrm{Pb}^{2+}$} & 0 & 0.0279 & - \\
\hline & 0.02 & 0.0488 & 104.5 \\
\hline & 0.05 & 0.0766 & 97.4 \\
\hline \multirow{3}{*}{$\mathrm{Cd}^{2+}$} & 0 & 0.0024 & - \\
\hline & 0.002 & 0.0043 & 95 \\
\hline & 0.005 & 0.0071 & 94 \\
\hline \multirow{3}{*}{$\mathrm{Zn}^{2+}$} & 0 & 0.9315 & - \\
\hline & 0.5 & 1.4085 & 95.4 \\
\hline & 1 & 1.9703 & 103.88 \\
\hline \multirow{3}{*}{$\mathrm{Ni}^{2+}$} & 0 & 0.0218 & - \\
\hline & 0.01 & 0.0309 & 91 \\
\hline & 0.05 & 0.0711 & 98.6 \\
\hline \multirow{3}{*}{$\mathrm{Cu}^{2+}$} & 0 & 1.0416 & - \\
\hline & 0.5 & 1.5399 & 99.66 \\
\hline & 1 & 1.9862 & 94.46 \\
\hline \multirow{3}{*}{$\mathrm{Ag}^{2+}$} & 0 & 0.019 & - \\
\hline & 0.01 & 0.0291 & 101 \\
\hline & 0.02 & 0.0386 & 98 \\
\hline
\end{tabular}

retained at $\mathrm{pH} 5-9$; their adsorption capacities of GFBT for $\mathrm{Pb}^{2+}, \mathrm{Cd}^{2+}, \mathrm{Zn}^{2+}, \mathrm{Ni}^{2+}, \mathrm{Cu}^{2+}$ and $\mathrm{Ag}^{+}$were $155.93,22.38,35.98$, $3.97,81.92$ and $15.32 \mathrm{mg} / \mathrm{g}$, respectively. The adsorbent can be regenerated completely by elution with $1 \mathrm{~mol} / \mathrm{L} \mathrm{HNO}_{3}$. The adsorbent can be used for at least 10 adsorption-elution cycles without observable change in performance. The adsorbent has been used for their preconcentration from various aqueous solutions. The proposed method based on preconcentration with GFBT and determination by FAAS showed enough sensitivity for those trace heavy metal ions in water determinations. The precision and accuracy were satisfactory.

\section{REFERENCES}

1. State Environmental Protection Administration of China: Analysis Method of Water and Waste Water, China Environmental Science Press, Inc. Beijing, end. 4, pp. 286-415 (2002).

2. F. Pena-Pereira, I. Lavilla, C. Bendicho, F. Pena-Pereira, I. Lavilla and C. Bendicho, Spectrochim. Acta B, 64, 1 (2009).

3. V.N. Bulut, D. Ozdes, O. Bekircan, A. Gundogdu, C. Duran and M. Soylak, Anal. Chim. Acta, 632, 35 (2009).

4. I. López-García, P. Viñas, R. Romero-Romero and M. HernándezCórdoba, Talanta, 78, 1458 (2009).

5. T.A. Maranhão, E. Martendal, D.L.G. Borges, E. Carasek, B. Welz and A.J. Curtius, Spectrochim. Acta B, 62, 1019 (2007).

6. J.L. Burguera and M. Burguera, Spectrochim. Acta B, 64, 451 (2009).

7. V.K. Jain, H.C. Mandalia, H.S. Gupte and D.J. Vyas, Talanta, 79, 1331 (2009).

8. C.K. Christou and A.N. Anthemidis, Talanta, 78, 144 (2009).

9. I. Dakova, I. Karadjova, V. Georgieva and G. Georgiev, Talanta, 78, 523 (2009).

10. D. Zhang, H.D. Su and H. Gao, Spectrosc. Spect. Anal., 28, 218 (2008).

11. D. Zhang and P. Hou, Acta Chim. Sin., 67, 1336 (2009).

12. D. Zhang, W.-J. Zhang, X. Guan, H. Gao and H.-B. He, Spectrosc. Spect. Anal., 29, 693 (2009).

13. D. Zhang, Z.-G. Yuan, X. Guan and W.-J. Zhang, Rare Metal Mater. Eng., 38, 2207 (2009).

14. D. Zhang, P. Yu and X. He, J. AOAC Int., 93, 1925 (2011).

15. D. Zhang, Asian J. Chem., 24, 5219 (2012). 